\title{
Post-meiotic apozygotic combinatory process in sugar beet (Beta vulgaris L.)
}

\author{
Evgenii Vladimirovich Levites, Svetlana Sergeevna Kirikovich
}

Institute of Cytology and Genetics, Siberian Branch of the Russian Academy of Sciences, Novosibirsk, Russia

Email: elevites@ngs.ru, svetak@,bionet.nsc.ru

Received 9 October 2011; revised 10 November 2011; accepted 14 December 2011

\begin{abstract}
The effect of colchicine on phenotypic classes ratio of the enzyme locus controlling alcohol dehydrogenase (ADH1) in sugar beet agamospermous progenies was analysed. The obtained data are indicative of the thing that colchicine causes polytenization of homological chromosome regions carrying marker locus Adh1 alleles. Theoretical calculation of the formation of egg cells frequencies and those of further development of cells entering embryogenesis without fertilization, also the diminution calculation of excessive chromosome regions carrying marker locus alleles have been made. The coincidence of theoretical and experimental ratios of phenotypic classes indicates the existence of post-meiotic apozygotic combinatory process in plants.
\end{abstract}

Keywords: Alcohol Dehydrogenase; Colchicine; Polyteny; Diminution; Sugar Beet

\section{INTRODUCTION}

To explain the variability in agamospermous plant progenies, including sugar beet, a hypothesis based on the supposition about chromosome polyteny in cells of plant capable of setting seeds by agamospermy and about the diminution of excessive chromatids from a cell that has entered embryogenesis was suggested [1,2]. This hypothesis is based on the investigation results of agamospermy in sugar beet [3-6] and the known literary data on polyteny and chromatin diminution in animals and plants during the first divisions in embryogenesis [7-13].

It is supposed that chromosome polyteny in plant generative organs is differential and various chromosome sites have a different endoreduplication degree $[1,2]$. Diminution of excessive chromatids or copies of allelic chromatid regions is independent and equiprobable, and it is only the one pair of allelic chromatid regions attached to the nuclear membrane or nuclear matrix that remains in a cell that has entered embryogenesis $[1,2]$. A pair of allelic chromatid regions carrying marker locus alleles and preserved in this cell determines the genotype of a developing embryo. An equal diminution probability of excessive chromatid regions copies leads to the combinatory process which determines the ratio of phenotypic classes in an agamospermous progeny. As a result of this combinatory process the ratio of phenotypic classes in an agamospermous progeny is determined by the ratio of number of chromatid threads carrying marker alleles in a mother plant $[1,2]$.

Alongside with polyteny, polyploidy and, to be more precise, mixoploidy expressed as an admixture of tetraploid cells [14] among the bulk of diploid ones, may be a reason for agamospermous plant progenies variability. If a tetraploid mother cell of megaspores enters meiosis, then it gives rise to a diploid megaspore from which, during further divisions, an embryosac, having diploid cells capable of entering embryogenesis without a male gametes [14], is forming.

The phenotypic ratio in agamospermous progenies is determined by combinatory processes different in their nature, such as chromosome divergence in meiosis and also loss of excessive copies of chromatid regions by a cell that has entered embryogenesis. Both these processes may proceed under the agamospermous progeny formation of one and the same plant. Therefore, comparison of each of these processes contribution to the revealed polymorphism is of great concern. In connection with the above-formulated, the aim of the present study was searching for an experimental proof of the proposed theoretical model and accepted approximations.

\section{MATERIAL AND METHODS}

Agamospermous progenies of two pollen-sterile plants from the collection of Plant Populational Genetics Laboratory, ICG SB RAS, were involved in the study. Before germination, seeds of this progenies were treated with $0.1 \%$ colchicine solution under the conditions that affected the genome but did not lead to plant polyploidization (during 6 hours at $18^{\circ} \mathrm{C}$ in the dark); then they were 
washed in flowing water, germinated in the thermostat and planted in the hydroponic greenhouse. Control plants were grown from untreated seeds. The developed roots were subjected to vernalization and, after vernalization, plants were grown in the ground. During flowering, plants having only non-functional pollen, belonging to $m s 0$ and $m s 1$ according to F. W. Owen classification [15] were left in the field, fertile and semi-fertile ones being eliminated. Flowering plants were isolated from alien pollen penetration with the help of unbleached calico isolators. Strict selection for pollen sterility and using the isolators were the necessary conditions in developing agamospermous plants. Isozyme alcohol dehydrogenase spectrum (ADH1, E.C. 1.1.1.1.) controlled by locus Adh 1 was used as a marker trait. Electrophoresis in starch gel and detection of isozymes were made according to the standard methods described earlier [16,17].

Theoretical calculations of phenotypic frequencies were arranged according to J. B. C. Haldane method based on the use of hypergeometrical scheme of probability distribution to describe combinatory processes [18].

\section{RESULTS AND DISCUSSION}

Polymorphism on alcohol dehydrogenase was revealed in the analyzed agamospermous progenies, each of progenies having three phenotypic classes (Figure 1, Table 1). Isozyme spectrum ADH1 of homozygous plants $A d h 1-F /$ Adh1-F (short-FF) and Adh1-S/Adh1-S (short-SS) is presented by one band in the electrophoregram with fast (FF) or slow (SS) electrophoretic mobility, respectively. Three-banded isozyme spectrum FS, easily distinguished from each of two types of homozygotes, is revealed in heterozygotes $A d h 1-F / A d h 1-S$ (short—FS) (Figure 1).

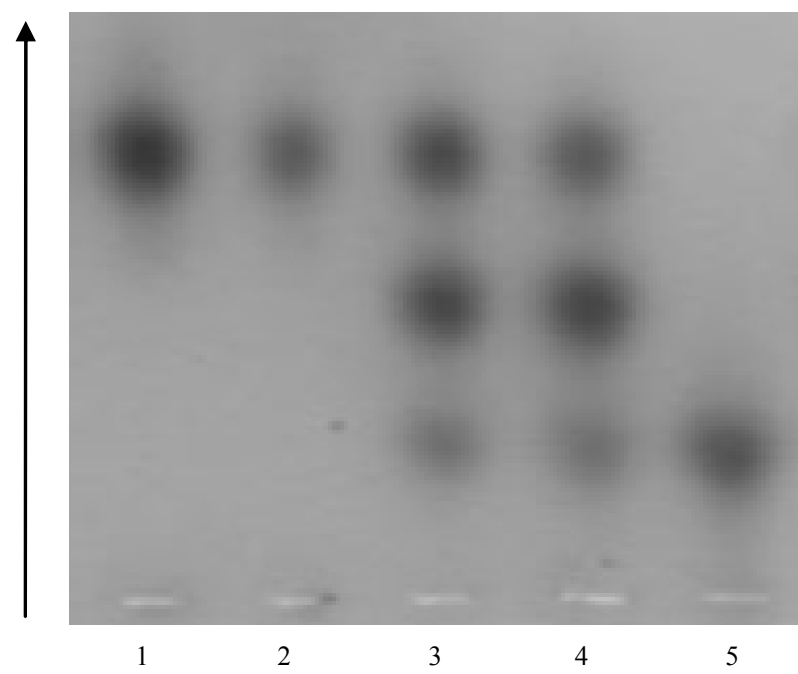

Figure 1. Isozyme patterns of alcohol dehydrogenase $(A d h 1)$ in sugar beet seeds. 1, 2-homozygote $A d h 1-F / A d h 1-F ; 3,4-$ heterozygote $A d h 1-F / A d h 1-S ; 5$ - homozygote $A d h 1-S / A d h 1-S$. Migration is toward the anode.
The symmetricity of the revealed ratio of phenotypes stands out (Table 1). It is indicative of the thing that, in these progenies formation, there was no pollination process usually accompanied by manifestation of self-incompatibility genes that lead to distortion of ratios of phenotypic classes [19].

The ratio of phenotypic classes $18 \mathrm{FF}: 48 \mathrm{FS}: 17 \mathrm{SS}$ in control agamospermous progeny No1-Contr well corresponds to the ratio $3: 8: 3\left(\chi^{2}=0.044 ; \mathrm{P}>0.05\right)$ which is typical of gametes in case when polymorphism is conditioned by the meiosis of tetraploid cells having two chromatids and, consequently, two copies of allele in each chromosome, i.e. FF FF SS SS (Table 1). This ratio is typical just of the case when segregation proceeds on the chromatid type (Table 1). A good correspondence to this segregation type was also revealed in experimental progenies of this form No1-Colch where the phenotypic ratio was 31FF:59FS:29SS $\left(\chi^{2}=2.858 ; \mathrm{P}>0.05\right)$. The correspondence to ratio $3: 8: 3$ is in favor of the supposition on the thing that cells which have entered embryogenesis developed as a result of tetraploid mother cell megaspores meiosis.

It is well known that, in polyploid cell meiosis, genetic segregation depends on the degree of marker-gene remoteness from the centromere. Segregation proceeds on chromosome type under close linkage of marker-gene with the centromere and the ratio of gametes, e.g. in the teraploid, is equal to 1:4:1 [18]. At this ratio, the share of heterozygotes is 0.668 , which is higher than that under chromatid segregation 3:8:3 typical of loci of a tetraploid which are distant from the centromere at more than 50\% of the cross-over [18]. In the tetraploid eight chromatids belonging to four chromosomes participate in chromatid segregation and, in this case, the share of heterozygotes is only 0.572 .

In form No1-Contr, the phenotypic ratio corresponds to both models $3: 8: 3$ and 1:4:1. However, in the experimental form No1-Colch, there is the correspondence only to ratio $3: 8: 3$ where the heterozygotes share is smaller (Table 1). The total phenotypic ratio 17FF:36FS:17SS in form No2-Contr progenies corresponds to ratio 3:8:3 $\left(\chi^{2}\right.$ $=0.933 ; \mathrm{P}>0.05)$, but it does not correspond to ratio $1: 4: 1\left(\chi^{2}=7.314 ; \mathrm{P}<0.05\right)$ which is connected with not a high heterozygotes share. The heterozygotes share is even smaller in the experimental progeny of this form No2-Colch. Here in the phenotypic ratio is 67FF:92FS: $68 \mathrm{SS}$ and it is significantly different from both ratios $3: 8: 3\left(\chi^{2}=25.596 ; \mathrm{P}<0.001\right)$ and $1: 4: 1\left(\chi^{2}=68.802 ; \mathrm{P}<\right.$ 0.001) (Table 1).

Thus, in both control groups (No1-Contr and No2Contr), the correspondence to ratio 3:8:3 is indicative of the thing that the segregation process is of chromatid type. However, in No2-Colch progeny, the revealed considerable decrease of heterozygotes share leading to the 
Table 1. Ratio of alcohol dehydrogenase (Adh1) phenotypic classes in sugar beet agamospermous plants.

\begin{tabular}{|c|c|c|c|c|c|c|}
\hline \multirow{2}{*}{ Studied form } & \multirow{2}{*}{$\begin{array}{l}\text { Experimental conditions, } \\
\text { number of plants }\end{array}$} & \multicolumn{3}{|c|}{ Adh 1 phenotypes } & \multirow{2}{*}{$\chi_{(3: 83)}^{2}$} & \multirow{2}{*}{$\chi_{(1: 4: 1)}^{2}$} \\
\hline & & $F F$ & $F S$ & SS & & \\
\hline \multirow{2}{*}{ No1 } & Control, $\mathrm{n}=1$ & 18 & 48 & 17 & 0.044 & 2.952 \\
\hline & Colchicine, $\mathrm{n}=2$ & 31 & 59 & 29 & 2.858 & $15.735^{* *}$ \\
\hline \multirow{2}{*}{ No2 } & Control, $n=3$ & 17 & 36 & 17 & 0.933 & $7.314^{*}$ \\
\hline & Colchicine, $\mathrm{n}=1$ & 67 & 92 & 68 & $25.596^{* *}$ & $68.802 * *$ \\
\hline
\end{tabular}

incorrespondence to ratio $3: 8: 3$ is indicative of the presence of additional factors that affect polymorphism in agamospermy.

An unusual phenotypic ratio in No2-Colch progeny can be accounted for by the thing that polymorphysm in the agamospermous progeny may be conditioned by several successive processes. In more detail these processes can be presented the following way: e.g. Tetraploid cells having genotype FFSS, respectively, were present in the bulk of diploid mother megaspore cells of plant No2Colch which is heterozygous $F S$ on the marker-locus. As a result of meiosis and chromatid segregation type, also further gametogenesis, diploid egg cells of three genotypes formed from these cells at ratio $3 F F: 8 F S: 3 S S$, and this can be expressed with the following sum of frequencies: $0.214 F F+0.572 F S+0.214 S S$. Polytenization of chromosomes occurred in egg cells under the delay of embryogenesis caused by the absence of pollen and merging of gametes. Also, pre-treatment of mother plant by colchicine contributed to this polytenization. Polytenization of marker-locus region in homoallelic cells carrying one allele does not lead to the combinatory process in the aftermath, whereas polytenization in heteroallelic cells carrying both marker-alleles does lead to the revealable combinatory process which determines the phenotypic classes ratio in a progeny. Suppose that, during embryogenetic delay, one polytenization cycle of chromosome regions carrying alleles $F$ and $S$ proceeded in diploid egg cells of genotype $F S$. Then these plant egg cells will have two copies of each of alleles. The state of the locus located in the polytenized chromosome region can be designated with the notion of "polygenotype" [20] which characterizes locus allelic composition, number of chromosomes and chromatids carrying each of alleles. In the considered situation, it is possible to designate the marker-locus polygenotype in heteroallelic cells as $F_{2} S_{2}$.

According to the earlier-suggested hypothesis, the embryogenesis-entered cell releases itself of the excess of whole chromatid copies or its certain regions [1,2]. It is supposed that diminution proceeds according to probability laws that allow us to calculate the genotypic ratio in a progeny. It is necessary to point out one more approximation.
The earlier-obtained numerous facts of the existence of abnormal and unexpected phenotypic classes in agamospermous progenies allow us to hypothesize that cross-over processes and exchange of chromatid regions of polytenized regions occur in an embryogenesis-entering cell before its first division. This means that a chromatid region belonging to one chromosome may be replaced by the analogous chromatid region belonging to other chromosome. Thus, we suppose that the same exchange of chromatid regions as during the first meiotic division occurs in an embryogenesis - entering cell at the moment of its first division. Also the specificity of recombination process in sugar beet that drastically differs it from many plant species and consists in, e.g. extreme localization of recombination points [21], indicates such a possibility.

Considering the accepted approximations, it is possible to calculate the frequencies of genotypes originating from diploid egg cells $F S$ that had polygenotype $F_{2} S_{2}$. From cells of polygenotype $F_{2} S_{2}$, as a result of equiprobable diminution of allelic copies, there occurs the three cell types formation at the following shares: $1 F F$ : $4 F S: 1 S S$, which can be expressed as a sum of frequencies: $0.166 F F+0.668 F S+0.166 S S$. This ratio coincides with those calculated by J. B. C. Haldane for the variants of two alleles chosen out of four among which there were two dominant and two recessive ones [18]. Thus, we obtain frequency $4 / 6$ for cells of genotype $F S$. Integrating expression $0.214 F F+0.572 F S+0.214 S S$ that describes the egg cells ratio with expression $0.166 F F+0.668 F S+$ $0.166 S S$ that describes the phenotypic ratio forming as a result of excessive chromatids diminution from egg cells $F S$, we obtain:

$$
\begin{aligned}
0 . & 214 F F+0.572 F S+0.214 S S \\
= & 0.214 F F+0.572(0.166 F F+0.668 F S+0.166 S S) \\
& +0.214 S S \\
= & (0.214+0.572 \times 0.166) F F+0.572 \times 0.668 F S \\
& +(0.214+0.572 \times 0.166) S S \\
= & 0.309 F F+0.382 F S+0.309 S S
\end{aligned}
$$

These calculations show that a certain part of heteroallelic egg cells, after diminution, gives rise to the embryos that add to classes of homoallelic genotypes and this leads to a decrease of heteroallelic ones. 
The experimentally found ratio $67 F F: 92 F S: 68 S S$ quite well accords with the theoretical one $\left(\chi^{2}=0.529, \mathrm{P}>\right.$ $0.05)$. It is indicative of the thing that the assumptions made are legitimate and the used model is correct. Thus, the obtained data contribute to the explanation of agamospermous plant progenies variability and allow us to state the thing that, alongside with known combinatory processes conditioned by chromosome divergence in meiosis and gametes random convergence, there exists one more post-meiotic combinatory process conditioned by chromosome polytenization and equiprobable diminution (loss) of excessive chromatid copies during the first divisions of embryogenesis.

A good correspondence of experimental to theoretical data also proves the supposition concerning the existence of exchange by chromatid regions among homological chromosomes in an embryogenesis-entering cell at the moment of its first division. Absence of a vividly expressed decrease of heterozygotes share in form No1Colch points out sugar beet plant polymorphism on the ability of chromosome regions polytenization.

Investigations of the whole number of species demonstrated the thing that colchicine causes inherited changes of many morphological and physiological traits without doubling of chromosome number [22-26]. The authors believe that the revealed changes are mutations. However, the drawback of these good, on the whole, studies - in our viewpoint - is that the control of chromosome number was not accompanied by measurement of DNA quantity in cells, i.e., in these researches, the possibility of the presence of polyteny that causes an increase of DNA content in the cell was not checked.

However, with the example of enzyme locus Gpi2, earlier we showed the thing that it is the increase of gene dosage with a high frequency leads to a change of its alleles [20] expression. This fact allows us to believe that, in treated plants, cochicine initiates a multi-step process whose first step is polytenization of different parts of genome leading to a change of expression of genes located in them. Such an outlook makes us closer to the explanation of colchicine effect which, in many authors standpoint, so far, remains unclear [22-26].

The data we obtained herein and earlier [20], and those known from literature [27] point out the thing that the polytenization ability of homological chromosome regions is different. This allows us to believe that different degree of polyteny is one more type of genetic polymorphism. Besides, chromosome polytenization can be considered as an important mechanism of genome transformation and evolution.

\section{ACKNOWLEDGEMENTS}

The authors would like to express their gratitude to Alexander V.
Zhuravlev for the English version of this article. Investigations were carried out within Integration Project \#99 for 2009-2011, supported by Siberian Branch of the Russian Academy of Sciences.

\section{REFERENCES}

[1] Levites, E.V. (2005) Sugarbeet plants produced by agamospermy as a model for studying genome structure and function in higher plants. Sugar Tech, 7, 67-70. doi:10.1007/BF02942532

[2] Levites, E.V. (2007) Marker enzyme phenotype ratios in agamospermous sugarbeet progenies as a demonstration of multidimensional encoding of inherited information in plants. http://arxiv.org/abs/q-bio/0701027

[3] Maletskii, S.I., Levites, E.V., Maletskaya, E.I. and Ovechkina, O.N. (1998) Autosegregation and linked inheritance in the agamospermous progeny of sugar beet Beta vulgaris L. Russian Journal of Genetics, 34, 418424.

[4] Levites, E.V., Shkutnik, T., Ovechkina, O.N. and Maletskii, S.I. (1999) Pseudosegregation in the agamospermic progeny of male sterile plants of the sugar beet (Beta vulgaris L.). Doklady Biological Sciences, 365, 182-184.

[5] Maletskaya, E.I. and Maletskaya, S.S. (1999) The nuclear DNA mass variability in embryo root cells of sugarbeet. Sugar Tech, 1, 30-36. doi:10.1007/BF02945157

[6] Levites, E.V., Denisova, F.Sh., Kirikovich, S.S. and Judanova S.S. (Maletskaya S.S.) (2000) Ratios of phenotypes at the $A d h 1$ locus in the apozygotic offspring in sugarbeet $\left(\mathrm{C}_{1}\right.$ generation). Sugar Tech, 2, 26-30. doi:10.1007/BF02995582

[7] Nagl, W. (1981) Polytene chromosomes of plants. International Review of Cytology, 73, 21-53. doi:10.1016/S0074-7696(08)61285-1

[8] Zhimulev, I.F. (1992) Polytene chromosomes: Morphology and structure. Novosibirsk.

[9] Carvalheira, G. (2000) Plant polytene chromosomes. Genetics and Molecular Biology, 23, 1043-1050. doi:10.1590/S1415-47572000000400050

[10] Morozova, E.M. (2002) Additional nuclear DNA in cells of embryo sacs of Haemanthus albiflos and Ornithogalum caudatum. Biological Bulletin, 29, 192-195. doi:10.1023/A:1014371403332

[11] Mericle, L.W. and Mericle, R.P. (1970) Nuclear DNA complement in young proembryos of barlei. Mutation Research, 10, 508-518. doi:10.1016/0027-5107(70)90013-8

[12] Ermakov, I.P., Barantseva, L.M. and Matveeva, N.P. (1981) Cytochemical investigation of DNA during ovule development and early embryogenesis in Pinus sibirica Du Tour. Ontogenez, 12, 339-345.

[13] Rasch, E.M. and Wyngaard, G.A. (2001) Evidence for endoreduplication: Germ cell DNA levels prior to chromatin diminution in Mesocyclops edax. Journal of Histochemistry and Cytochemistry, 49, 795-796. doi:10.1177/002215540104900615

[14] Maletskii, S.I. and Maletskaya, E.I. (1996) Self-fertility 
and agamospermy in sugar beet Beta vulgaris L. Russian Journal of Genetics, 32, 1643-1650.

[15] Owen, F.V. (1945) Cytoplasmically inherited male sterility in sugar beet. Journal of Agricultural Research, 71, 423-440.

[16] Levites, E.V. (1986) Genetics of plant isozymes. Novosibirsk.

[17] Vallejos, C.E. (1983) Enzyme activity staining. Isozymes in plant genetics and breeding. Part A. Elsevier, Amsterdam, 469-515.

[18] Haldane, J.B.S. (1930) Theoretical Genetics of Autopolyploids. Journal of Genetics, 22, 359-372. doi:10.1007/BF02984197

[19] Maletskii, S.I. and Konovalov, A.A. (1985) The inheritance of alcohol dehydrogenase in sugarbeet. I. The analysis of deviations from monogene segregation. Russian Journal of Genetics, 21, 1527-1534.

[20] Levites, E.V. and Kirikovich, S.S. (2011) Autosegregation of enzyme loci in agamospermous progenies of triploid plants of sugar beet (Beta vulgaris L.). Russian Journal of Genetics, 47, 836-841. doi:10.1134/S102279541107012X

[21] Hallden, C., Hjerdin, A., Rading, I.M., Sall, T., Fridlundh, B., Johannisdottir, G., Tuvesson, S., Akesson, C., Nilsson, N.O. (1996) A high density RFLP linkage map of sugar beet. Genome, 39, 634-645. doi:10.1139/g96-081

[22] Hassan, L., Jones, R.N. and Posselt, U.K. (1989) A novel source of genetic variation in ryegrasses (Lolium multiflorum, L. perenne). Heredity, 63, 339-342.

doi: $10.1038 /$ hdy.1989.107

[23] Francis, A., Jones, R.N., Parker, J.S. and Posselt, U.K. (1990) Colchicine-induced heritable variation in cell size and chloroplast numbers in leaf mesophyll cells of diploid ryegrass (Lolium perenne L.). Euphytica, 49, 49-55. doi:10.1007/BF00024130

[24] Castro, C.M., Oliveira, A.C. and Calvaho, F.I.F. (2003) Changes in allele frequencies in colchicine treated Ryegrass population assessed with APD marker. Agrociencia, 9, 107-112.

[25] Rauf, S., Khan, I.A. and Khan, F.A. (2006) Colchicine-induced tetraploidy and changes in allele frequencies in colchicine-treated populations of diploids assessed with RAPD markers in Gossypium arboreum L. Turkish Journal of Biology, 30, 93-100.

[26] Mensah, J.K., Obadoni, B.O., Akomeah, P.A., Ikhajiagbe, B. and Ajibolu, J. (2007) The effects of sodium azide and colchicine treatments on morphological and yield traits of sesame seed (Sesame indicum L.). African Journal of Biotechnology, 6, 534-538.

[27] Cionini, P.G., Cavallini, A., Corsi, R. and Fogli, M. (1982) Comparison of homologous polytene chromosome in Phaseolus cocineus embryo suspensor cells: Morphological, autoradiographic and -cytophotometric analyses. Chromosoma, 86, 383-396. doi:10.1007/BF00292265 